\title{
Correction to: Emergence of CMY-2-Producing Escherichia coli in Korean Layer Parent Stock, by Seo KW, Shim JB, and Lee YJ. Microb. Drug Resist. 2019;25(3):462-468. DOI: $10.1089 / \mathrm{mdr} .2018 .0254$.
}

\footnotetext{
TN THE April 2019 issue of Microbial Drug Resistance (vol. 25, no. 3, pages 462-468), in the article entitled, Emergence $\mathbf{L}$ of CMY-2-Producing Escherichia coli in Korean Layer Parent Stock, by Kwang Won Seo, et al., incorrect funding information was published under Acknowledgments on page 467:
}

"This work was supported by Korea Institute of Planning and Evaluation for Technology in Food, Agriculture, Forestry, and Fisheries (IPET) through Agriculture, Food and Rural Affairs Research Center Support Program, funded by the Ministry of Agriculture, Food and Rural Affairs (MAFRA) (716002-7).,"

The funding information should have appeared as:

This work was carried out with the support of the Cooperative Research Program for Agriculture Science and Technology Development (Project No. PJ907012) Rural Development Administration, Republic of Korea.

The online version of the article has been corrected to reflect this change.

The authors apologize for this error. 